\title{
An Empirical Study on the Impact of Prior Information Provision Methods on Participants' Perceptions in Tasting Marketing
}

\author{
Hisashi Masuda $^{1(\bowtie)}\left(\mathbb{D}\right.$ and Kengo Matsumura ${ }^{2}$ \\ ${ }^{1}$ Kyoto University, Yoshida-honmachi, Sakyo-ku, Kyoto 606-8501, Japan \\ masuda.hisashi.4c@kyoto-u.ac.jp \\ 2 Gekkeikan Sake (USA), INC., 1136 Sibley Street, \\ Folsom, CA 95630-3223, USA
}

\begin{abstract}
Tasting events are a typical example of a tourism experience that utilizes alcohol. However, it has not been sufficiently demonstrated how the prior information given to customers at tasting events affects their perception of the tasting and its marketing effects. In this study, we conducted a tasting experiment of a new Japanese sake product in California, the USA to clarify how information given to participants in advance can affect their perception of the tasting, satisfaction, and word-of-mouth intention related to the new sake product, and compared the effects of the following types of prior information: 1) no information, 2) written information, 3) video explained by a man, and 4) video explained by a woman. The results show that presenting information makes a difference in its impact as opposed to providing no information. When prior information was presented in written form, various perspectives significantly influenced the satisfaction and recommended intention more than in the cases of video. On the other hand, in the cases of video, the number of significant paths was reduced, but the influence on word-of-mouth intention was greater than in the case of written information. This study contributes to the development of a theory and empirical evidence that takes into account prior information in tasting marketing in tourism.
\end{abstract}

Keywords: Tasting event $\cdot$ Tasting perception $\cdot$ Word-of-mouth $\cdot$ Prior information provision $\cdot$ Japanese sake

\section{Introduction}

Past studies have indicated that there are synergies between wine tourism and wine production, and underlining the importance of regional development and the experiential wine tourist [1]. In this context, tasting events have become a typical tourist experience [2] in wine-producing regions. This kind of experience based on the use of locally produced alcohol is one of the essential attractions in a tourist destination.

In Japan, there is a rice-based alcoholic beverage called Japanese sake that can be compared to wine tourism. Similar to wine tourism, sake tourism is also flourishing in 
Japan, on the basis of the long history and the appeal of the cultural aspect in sake brewers [3].

With regard to the study of alcohol, various perceptions have been analyzed in the context of beer. Consumer variables (demographic variables, psychographic and behavioral variables, genetic variables), product variables (product-intrinsic attributes, product-extrinsic attributes), and context and the purchase process (the customer journey, atmospherics) have been identified as factors related to the choice of beer [4]. In particular in tasting events in beer, an analysis of how tasting different types of beer (e.g., mass-produced vs. craft beer) affects consumers has also been demonstrated [5].

However, it has not been sufficiently demonstrated how the prior information given to customers when enjoying alcohol at tasting events influences their perceptions of the tasting and its marketing effects. In recent years, influencer marketing has been gaining importance, and the influence of social media (e.g., YouTube) using video, in particular, has been growing [6].

Therefore, this research purpose is to clarify the effects of such information provision on alcohol-based tourism experiences. Theoretically, we would contribute to the development of a theory for evaluating the impact of prior information provision to customers in tasting marketing. On the practical side, it provides insights to help companies or DMOs (destination marketing organizations) make decisions on how to design more effective tasting marketing, taking into account the impact on the customer experience of providing information to customers in advance.

\section{Research Model}

In order to achieve the proposed objectives in this study, we set up a research model as shown in Fig. 1 based on our hypotheses. For the marketing outcomes, product satisfaction and product word-of-mouth intention constructs were set, and also, the sensory perception construct, cognitive perception construct, and affective perception construct are developed based on previous studies [4, 5, 7]. Regarding the control variables, based on our research objectives, we set up that the prior information given to the participants of a tasting event makes a difference in product satisfaction and word-of-mouth marketing effectiveness. The types of prior information are specifically: 1) no prior information, 2) written information, 3) video with a man explaining, and 4) video with a woman explaining.

\section{Methodology}

To test the proposed research model, we conduct an experiment on new Japanese sake tasting among customers of Japanese restaurants in California, USA. In this study, before joining the tasting experiment, participants are controlled with different means providing prior information about the new product. Specifically, the participants are randomly divided into four groups: 1) no explanation of the prior information of the new product, 2) explanation of the prior information in text, 3) explanation in a video by a person (male), and 4) explanation in a video by a person (female). As the content 
of information, the same description of the new product (brand-new Japanese Sake) is used for groups 2-4. Participants of group 1 join the tasting experiment without any prior information about the new product. As the used product for the tasting marketing, we set one of the new sake products of a Japanese Sake company. The new product differs greatly from traditional sake in terms of flavor. In conducting this research, we underwent a research ethics review at the Graduate School of Management, Kyoto University, and obtained approval formally for the experiment plan.

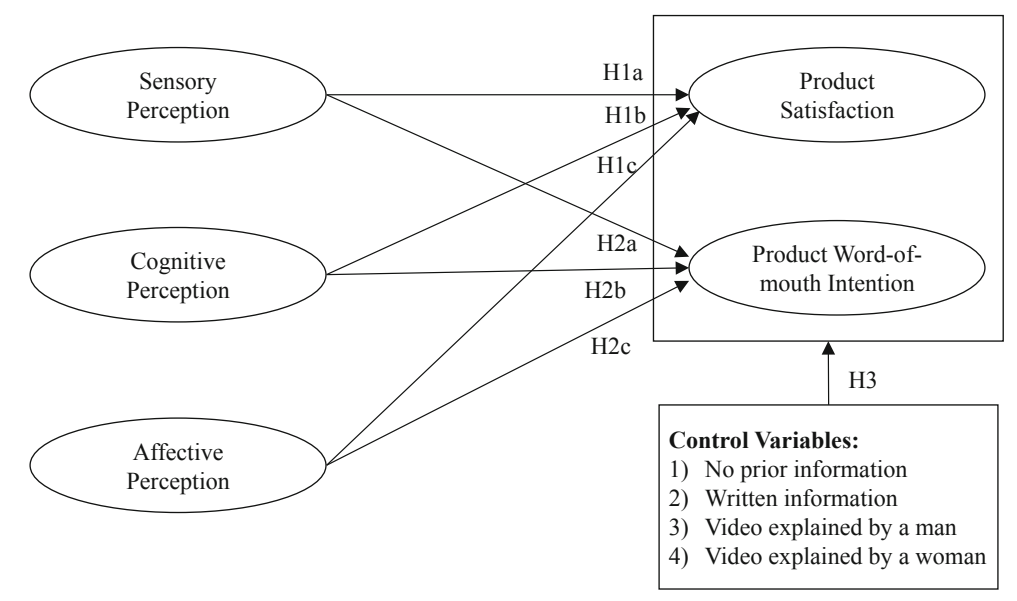

Fig. 1. Proposed research model.

A questionnaire for the experiment was designed to collect feedback on the tasting experience from the participants based on the proposed research model. The first item is to select the category of what type of prior information they gained: 1) no prior information, 2) written information, 3) video with a man explaining, and 4) video with a woman explaining. The main question items were constructs of the research model, and the degree to which the following perspectives agreed was collected using a 5point Likert scale. The sensory perception consists of aroma, sweet, dry, sour, stiff, mellow, complicated, fresh, juicy(fruity), watery/bland, aftertaste, and white wine taste. The cognitive perception consists of artisan, balanced, cheap, easy-to-drink/drinkable, sophisticated, familiar, casual, novel, light/full body, mass-produced, masculine, simple, smooth, strong, unique, craft sake, and authentic. The affective perception consists of memorable, exciting, comfortable, fun, adventurous, relaxing, and stimulating. The marketing KPIs (Key Performance Indicators) are product satisfaction and product word-of-mouth intention. In addition, demographic and psychographic attributes related to alcohol were collected for each participant.

Data were collected at two Japanese restaurants in California, the USA between July $12-15,2021$. After agreeing to the purpose and the procedure of the experiment, participants were randomly assigned to the prior information acquisition types. Then, they had a tasting of a new Japanese sake product with the preliminary information provision type of each group. After tasting, participants answered the web questionnaire using 
mobile devices. The number of validated responses was 132 (Restaurant A: 55, Restaurant B: 77). Demographic attributes and prior information types are shown in Table 1.

The method of hypothesis testing is Partial Least-squares-based Structural Equation Modeling (PLS-SEM) [9]. This is more suitable for this study than Covariance-based Structural Equation Modeling (CB-SEM) because it allows for more robust analysis with smaller sample size.

Table 1. Demographic characteristics of participants and prior information Type $(\mathrm{N}=132)$.

\begin{tabular}{|c|c|c|c|c|c|}
\hline \multirow[t]{3}{*}{ Gender } & Male & $53.8 \%$ & Income level & Less than US\$50,000 & $15.9 \%$ \\
\hline & Female & $43.2 \%$ & & US\$50,000-99,999 & $32.6 \%$ \\
\hline & Others/Prefer not to say & $3.0 \%$ & & US\$100,000+ & $31.8 \%$ \\
\hline \multirow[t]{5}{*}{ Age(years) } & $21-29$ & $15.2 \%$ & & Prefer not to say & $19.7 \%$ \\
\hline & $30-39$ & $25.0 \%$ & Educational level & Middle schol & $0.8 \%$ \\
\hline & $40-49$ & $22.0 \%$ & & High school & $18.9 \%$ \\
\hline & $50-59$ & $25.8 \%$ & & University/College(Bachelor) & $47.7 \%$ \\
\hline & $60+$ & $12.1 \%$ & & Graduate School(Master) or higher & $14.4 \%$ \\
\hline \multirow[t]{6}{*}{ Racial Identity } & White & $66.2 \%$ & & Vocational School & $8.3 \%$ \\
\hline & Latino/a/x or Hispanic & $11.0 \%$ & & Others/Prefer not to say & $9.9 \%$ \\
\hline & African American & $3.7 \%$ & Prior Information Type & No prior information & $24.2 \%$ \\
\hline & American Indian or Alaska Native & $3.7 \%$ & & Written information & $22.7 \%$ \\
\hline & Asian & $2.9 \%$ & & Video explained by a man & $26.5 \%$ \\
\hline & Others/Prefer not to say & $12.5 \%$ & & Video explained by a woman & $26.5 \%$ \\
\hline
\end{tabular}

\section{Results}

Results are presented in Table 2. First of all, it was shown that the way in which prior information is provided makes a difference in the impact on product satisfaction and intention to recommend. When prior information was presented in written form, various perspectives significantly influenced satisfaction and recommended intention more than in the cases of video, although the significance level is 0.05 . In the cases of video, the number of significant relationships was reduced, but we obtained paths with stronger relationships with significance levels below 0.01 than the written information case. In particular, especially for male videos, affective perception significantly influenced product recommendation intentions, and also, sensory and affective perception also had a significant impact on product satisfaction. On the other hand, the significant paths decreased for female videos, but there was an impact of sensory perception on product recommendation intention with a significant level of 0.01 .

\section{Discussion}

The results of this study showed that providing prior information in a tasting event can influence relationships between participants' perceptions (sensory, cognitive, and affective) and their product satisfaction and product word-of-mouth intentions. In particular, it was shown that explaining prior information through video strongly influences the product word-of-mouth intention. This research contributes to the 
development of a theoretical foundation for evaluating the provision of tourism experiences of tastings. On a practical side, it also provides insights into the means of providing prior information when offering tourism experiences. On the other hand, in this experiment, a video by women reduced the number of significant paths more than those of written information. This may indicate the variation in the evaluation criteria for female videos among the experimental participants against other means. Therefore, it is necessary to subdivide the group in order to examine the effect in detail. In the future, we need to work on theoretical development, taking into account the analysis of customer attributes in detail and the credibility of the information sender in videos.

Table 2. Results of hypothesis testing (H1-H3).

\begin{tabular}{|c|c|c|c|c|c|c|c|c|c|}
\hline \multirow[b]{2}{*}{ Hypothesis/Structural path } & \multicolumn{2}{|c|}{$\begin{array}{l}\text { No prior } \\
\text { information } \\
(\mathrm{N}=32)\end{array}$} & \multicolumn{2}{|c|}{$\begin{array}{c}\text { Written } \\
\text { information } \\
(\mathrm{N}=30)\end{array}$} & \multicolumn{2}{|c|}{$\begin{array}{c}\text { Video } \\
\text { explained } \\
\text { by a man } \\
(\mathrm{N}=35)\end{array}$} & \multicolumn{2}{|c|}{$\begin{array}{c}\text { Video } \\
\text { explained } \\
\text { by a woman } \\
(\mathrm{N}=35)\end{array}$} & \multirow{2}{*}{$\begin{array}{c}\begin{array}{c}\text { Difference } \\
\text { between } \\
\text { the groups } \\
(\mathrm{H} 3)\end{array} \\
\text { Result } \\
\end{array}$} \\
\hline & $\beta$ & Result & $\beta$ & Result & $\beta$ & Result & $\beta$ & Result & \\
\hline H1a Sensory Perception $\rightarrow$ Product Satisfaction & 0.343 & $\mathrm{R}$ & 0.245 & $\mathrm{R}$ & $0.527 * *$ & A & 0.335 & $\mathrm{R}$ & A \\
\hline H1b Cognitive Perception $\rightarrow$ Product Satisfaction & 0.064 & $\mathrm{R}$ & 0.218 & $\mathrm{R}$ & $0.402 *$ & $\mathbf{A}$ & 0.205 & $\mathrm{R}$ & $\mathbf{A}$ \\
\hline H1c Affective Perception $\rightarrow$ Product Satisfaction & 0.339 & $\mathrm{R}$ & $0.478 *$ & $\mathbf{A}$ & $0.376^{* *}$ & $\mathbf{A}$ & 0.226 & $\mathrm{R}$ & $\mathbf{A}$ \\
\hline H2a Sensory Perception $\rightarrow$ Product Word-of-mouth Intention & 0.228 & $\mathrm{R}$ & $0.391 *$ & $\mathbf{A}$ & -0.205 & $\mathrm{R}$ & $0.545^{* *}$ & $\mathbf{A}$ & $\mathbf{A}$ \\
\hline H2b Cognitive Perception $\rightarrow$ Product Word-of-mouth Intention & 0.230 & $\mathrm{R}$ & $0.370^{*}$ & $\mathbf{A}$ & -0.028 & $\mathrm{R}$ & 0.205 & $\mathrm{R}$ & $\mathbf{A}$ \\
\hline H2c Affective Perception $\rightarrow$ Product Word-of-mouth Intention & $0.478 *$ & $\mathbf{A}$ & $0.475 *$ & $\mathbf{A}$ & $0.799 * * *$ & $\mathbf{A}$ & 0.007 & $\mathrm{R}$ & $\mathbf{A}$ \\
\hline
\end{tabular}
Note: Two Tailed Test; $* * *$ Significance Level $=0.1 \% ; * *$ Significance Level $=1 \%$; Significance Level $=5 \%$; $\mathrm{A}=$ Accepted; $\mathrm{R}=$ Rejected

\section{References}

1. Gómez M, Pratt MA, Molina A (2019) Wine tourism research: a systematic review of 20 vintages from 1995 to 2014. Curr Issue Tour 22(18):2211-2249

2. Dawson H, Holmes M, Jacobs H, Wade RI (2011) Wine tourism: winery visitation in the wine appellations of Ontario. J Vacat Mark 17(3):237-246

3. Lee YS, Shin WJ (2015) Marketing tradition-bound products through storytelling: a case study of a Japanese sake brewery. Serv Bus 9(2):281-295

4. Betancur MI, Motoki K, Spence C, Velasco C (2020) Factors influencing the choice of beer: a review. Food Res Int 137:109367

5. Jaeger SR, Worch T, Phelps T, Jin D, Cardello AV (2020) Preference segments among declared craft beer drinkers: perceptual, attitudinal and behavioral responses underlying craftstyle vs. traditional-style flavor preferences. Food Qual. Prefer 82:103884

6. Masuda H, Han SH, Lee J (2022) Impacts of influencer attributes on purchase intentions in social media influencer marketing: mediating roles characterizations. Technol. Forecast Soc Change 174:121246

7. Ares G, Jaeger SR (2015) 11 - Check-all-that-apply (CATA) questions with consumers in practice: experimental considerations and impact on outcome. In Delarue J. Lawlor JB, Rogeaux M (eds.) Rapid sensory profiling techniques: woodhead publishing 
8. Jaeger SR, Cardello AV, Chheang SL, Beresford MK, Hedderley DI, Pineau B (2017) Holistic and consumer-centric assessment of beer: a multi-measurement approach. Food Res Int 99:287-297

9. Hair JF, Hult GTM, Ringle CM, Sarstedt M (2022) A Primer on Partial Least Squares Structural Equation Modeling. SAGE Publications, PLS-SEM) Third Edition

Open Access This chapter is licensed under the terms of the Creative Commons Attribution 4.0 International License (http://creativecommons.org/licenses/by/4.0/), which permits use, sharing, adaptation, distribution and reproduction in any medium or format, as long as you give appropriate credit to the original author(s) and the source, provide a link to the Creative Commons license and indicate if changes were made.

The images or other third party material in this chapter are included in the chapter's Creative Commons license, unless indicated otherwise in a credit line to the material. If material is not included in the chapter's Creative Commons license and your intended use is not permitted by statutory regulation or exceeds the permitted use, you will need to obtain permission directly from the copyright holder. 